\title{
Performance of up-flow anaerobic sludge blanket followed by continuous-flow sequencing batch reactor
}

\author{
Abdelsalam Elawwad', Mohamed Hazem¹, Hisham Abdel-Halim ${ }^{1}$ \\ ${ }^{1}$ Environmental Engineering Dept., Faculty of Engineering, Cairo University \\ 12613 Giza, Egypt. \\ elawwad@cu.edu.eg; mmhazem83@gmail.com; hishama.halim2011@gmail.com
}

\begin{abstract}
A system consists of an up-flow anaerobic sludge blanket (UASB) and a continuous flow sequencing batch reactor (contflow SBR) was operated under different retention times. UASB was tested at 2.8, 4.4, then $5.7 \mathrm{hrs}$. The average chemical oxygen demand (COD) removal in UASB was $51.5 \%$ on average. Cont-flow SBR was tested at 4 to 6 and then at 8 hrs cycle periods. The results indicated that the ability of the pilot plant to work under different retention times with removal efficiencies for COD, TN, and phosphate up to $96.5 \%, 62.6 \%$, and $35.9 \%$ respectively. The main advantage of the proposed treatment system is the minimization of investment and operational costs as compared to the use of cont-flow SBR systems alone.
\end{abstract}

Keywords: Cont-flow SBR; UASB; wastewater, retention time.

\section{Introduction}

Wastewater must be treated before discharge into the environment as it contains many harmful pollutants [1]. One of the treatment technologies that has been successful used in the last decades is the upflow anaerobic sludge blanket (UASB). The UASB effluent may not meet the required effluent standards even with high organic matter removal efficiency, therefore a post-treatment to the UASB reactor effluent may be essential [2]. Recently, sequencing batch reactor (SBR) technology is of great interest for decentralized wastewater treatment due to its operational flexibility. The sequencing batch reactors SBR systems have been recently examined as they have an important benefit for biological nutrients elimination [2, 3].

The conventional SBR system has a superior removal efficiency, however, it does have some disadvantages in terms of its difficult operation and control system. A modification for SBR called the continuous flow SBR (cont-flow SBR) permits continuous influent flow of wastewater to the reactor [4]. Wastewater inflow to the tank is not stopped during the settling and decanting period or at any period during the operation. In normal SBR there are five stages: filling, reacting, settling, drawing, and idling but in cont-flow SBR there are only three phases: react, settle, and draw [3, 4]. Cont-flow SBR needs less control and has a simple configuration compared with a conventional SBR. The only disadvantage for cont-flow SBR is that it has a lower removal efficiency than normal SBR as the efficiency of the settling process is reduced due to the dilution effect from the nonstop influent sewage flow. Therefore, cont-flow SBR to be more suggested for decentralized regions where less environmental restrictions might be applied [3].

The combination of UASB and SBR or cont-flow SBR was suggested by different authors in the literature. According to Khan et al. [5], the removal efficiencies in an integrated system of UASB and SBR could reach up to 90,83 and $74 \%$ for TSS, BOD and $\mathrm{NH}_{4}-\mathrm{N}$, respectively. In addition, combining UASB with SBR systems could lead to a high reduction in energy consumption and sludge production $[3,6]$.

This paper presents and discusses the results obtained during the operation of a pilot plant composed of a UASB reactor followed by an aerobic cont-flow SBR treating domestic sewage. The aim of the study was to investigate changing retention time on the pilot plant performance. The performance of the system was evaluated for the removal of organic matter, nitrogen in addition to gas production. The proposed scheme in this study could be a promising and cost-effective option for decentralized and small communities which suffer in many countries (such as Egypt) from lack of appropriate sanitation services [7]. 


\section{Methodology}

A treatment system consisted of a UASB followed by cont-flow SBR was constructed at El-Berka sewage treatment plant (WWTP), Egypt. The system consists of a 50-liters UASB reactor and a cont-flow SBR with a volume of 180 litres. The wastewater is primary treated by the UASB, then the partially treated wastewater is directed to the cont-flow SBR. Raw domestic wastewater was continuously pumped to the pilot plant as shown in Figure 1. More details and description for the pilot plant can be found in our previous paper [3].

The average influent wastewater characteristics were COD=553 $\pm 266 \mathrm{mg} / \mathrm{l}, \mathrm{BOD}=332 \pm 160 \mathrm{mg} / \mathrm{l}, \mathrm{TSS}=293 \pm 197 \mathrm{mg} / \mathrm{l}$, $\mathrm{VSS}=232 \pm 147 \mathrm{mg} / \mathrm{l}$, and TN $=38.9 \pm 8.7 \mathrm{mg} / \mathrm{l}$. This WWTP receives domestic wastewater from different villages and decentralized areas in Greater Cairo. The pilot plant was operated for more than 365 days at the ambient temperature (Minimum temp. $15^{\circ} \mathrm{C}$, Maximum temp. $30^{\circ} \mathrm{C}$ ) at El-Berka WWTP. The cont-flow SBR was operated at sludge retention time (SRT) of 20 days.

The effect of a change in retention time on the performance of the system was tested. For this purpose, the system was tested under three different retention times in UASB and cycle periods in cont-flow SBR (Table 2). UASB HRT respectively varied from 1.45 to 2.28 then 2.90, the cycle period of cont-flow SBR was respectively varied from 4 to 6 and then to $8 \mathrm{~h}$ for experimental runs 1,2 , and 3, re times of $4,6,8 \mathrm{hr}$ respectively. The fill ratio of cont-flow SBR was adjusted between 35 to $45 \%$ along the experimental period. The time of the sequencing aeration-decanting system was controlled by a timer. The aeration periods were $2.75,4.75$, and $6.75 \mathrm{hr}$ corresponding to cycle trolled by a timer. The settling period and decanting periods were set to about 1.1 and $0.15 \mathrm{hr}$ respectively. The cont-flow SBR was operated at SRT of 20 days for experimental runs 1 to 3. Excess sludge was discharged manually from UASB which is calculated by dividing the volume of the tank (180 Liters) on the 20 days, so 9 litres of excess sludge is wasted daily.

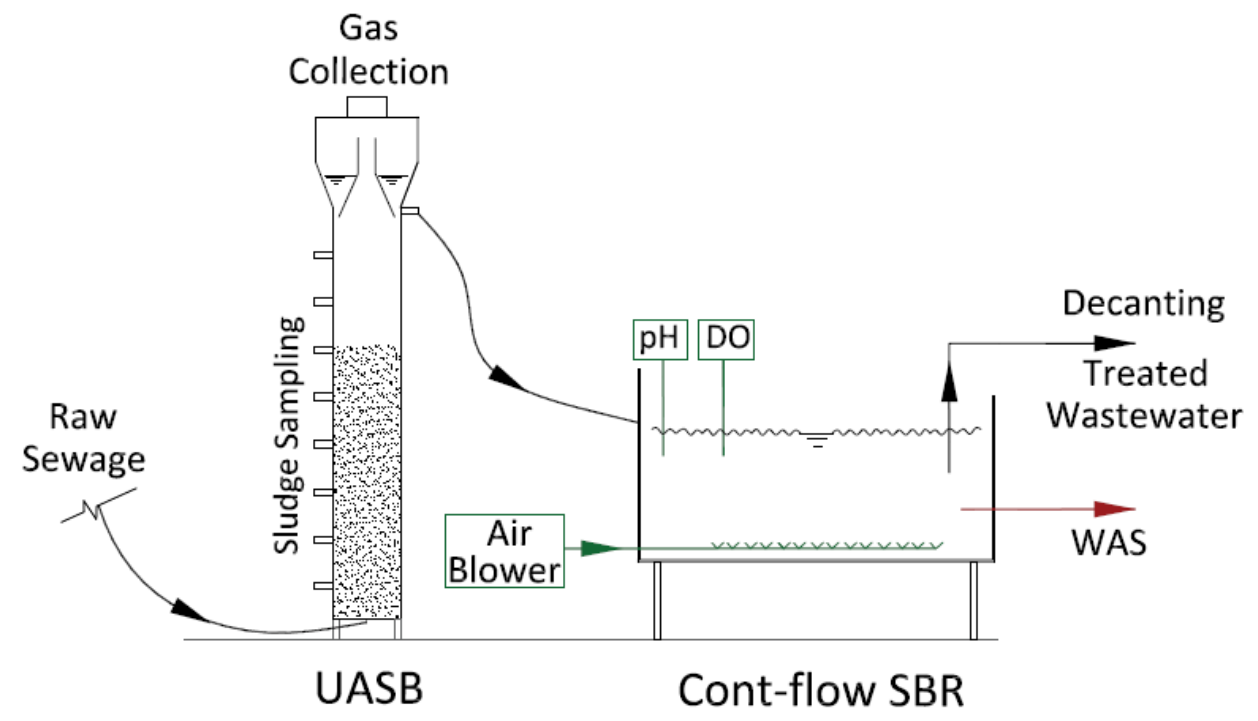

Figure 1: Schematic diagram for the combined UASB and cont-flow SBR.

The parameters chemical oxygen demand (COD), and biochemical oxygen demand (BOD5) total suspended solids (TSS), volatile suspended solids (VSS), temperature, ammonia-nitrogen $\left(\mathrm{NH}_{4}-\mathrm{N}\right)$, total nitrogen (TN), total phosphorus (TP), $\mathrm{pH}, \mathrm{DO}$ and alkalinity was determined for each sample. The gas production rate was measured by water displacement method two times per week. All the analyses were carried out in accordance with the standard methods [8].

\section{Results}

After the steady state was reached, the hydraulic retention time in UASB and cycle time in cont-flow SBR was changed while the SRT was maintained constant at 5 days. In runs from 1 to 3, the effect of changing the HRT on the organic removal as well as nitrification and phosphorus removal was studied. The results of COD and ammonia are shown in figures 2 and 3. The average UASB COD efficiency in runs 1,2 and 3 was $50 \pm 4,47 \pm 6,56 \pm 11 \%$, respectively. The average COD removal efficiency for the whole system was $78 \pm 3,74 \pm 8,75 \pm 7 \%$, respectively. 


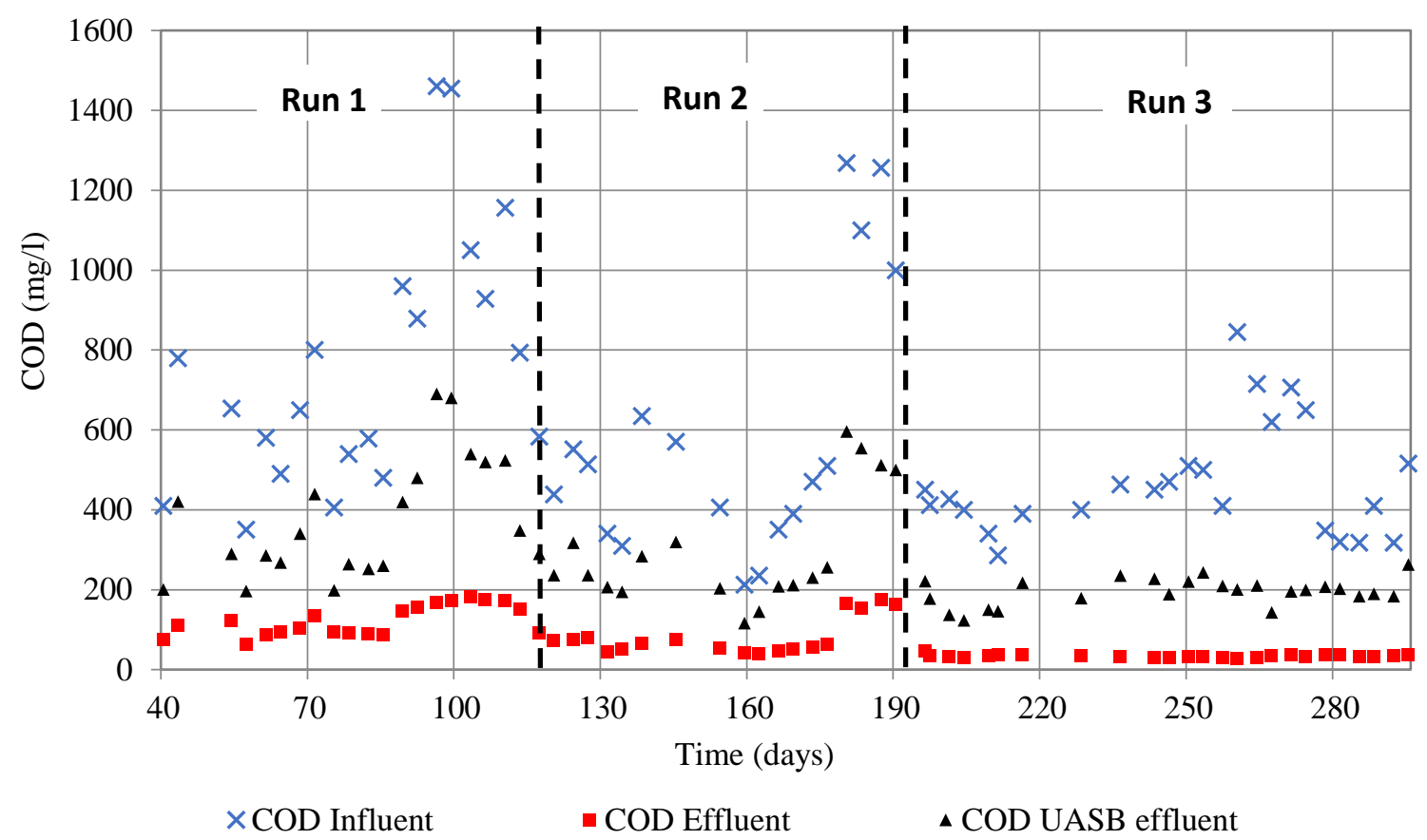

Figure 2: COD in the influent and UASB, cont-flow SBR effluent during runs 1, 2 and 3.

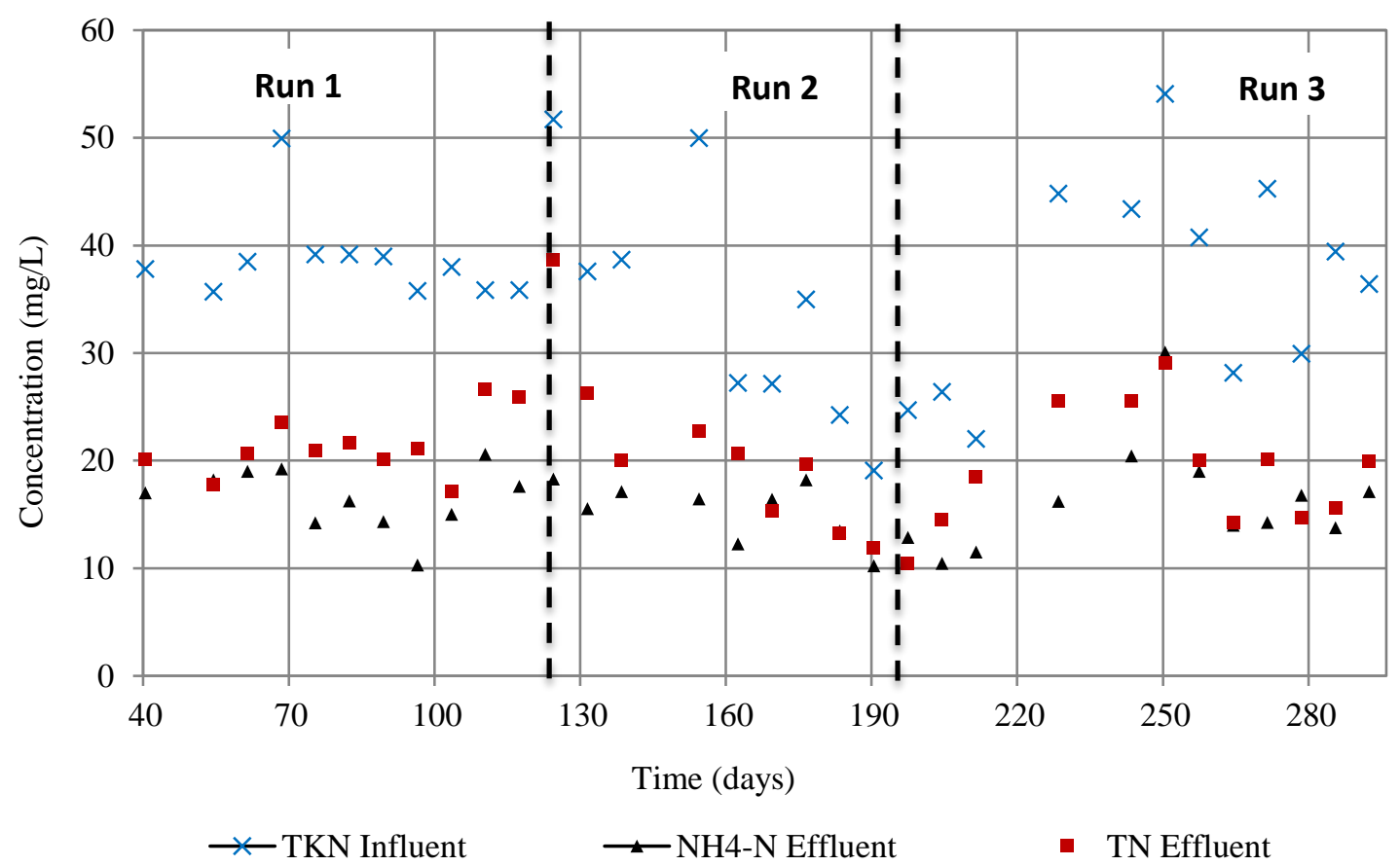

Figure 3: TKN in the influent and NH4-N \& TN in the effluent during runs 1, 2, and 3.

A peak flow duration was recorded in run 1 during the days from 96 to 103 raising the influent COD to a value of 1460 $\mathrm{mg} / \mathrm{L}$ (Figure 2), the system could overcome the overloading and achieved a max COD removal efficiency during the run 3. The Pilot Plant TSS\&VSS removal efficiency increased by increasing HRT as TSS\&VSS removal efficiency in run 2 and 3 is greater than run 1 . The average ammonia removal efficiency in runs 1,2 and 3 is $57,53,54 \%$ respectively. The average TN pilot plant efficiency in runs 1,2 and 3 is $48.2,43$, and $49.9 \%$ respectively. This indicates that there is no trend between TN pilot plant efficiency and changing UASB HRT and cont-flow SBR cycle time. 
The organic loading rate ranged between $(0.22-2.27) \mathrm{kg} / \mathrm{m}^{3} /$ day and the biogas production ranged between (37.1-275.3) $\mathrm{ml} / \mathrm{gm}$ COD removed which was relatively low if compared to the values mentioned in Tchobanoglous et al. [9]. On the other hand, it was near to the results reported by [10], which ranged between $(160-285) \mathrm{mL} / \mathrm{gm}$ COD for the same organic loading for domestic wastewater.

In the present study, the effluent efficiency was comparable to that of other integrated UASB-aerobic systems reported in the literature. Khan et al. [11] achieved BOD, TSS, and ammonia removal efficiencies of 83\%, 90\%, and 74\%, respectively, in a combined UASB-cont-flow SBR system. Torres and Foresti et al. [12] achieved a higher removal efficiency for COD, TSS, and TKN of 91\%, 84\%, and 90\%, respectively in a combined UASB-SBR system. Moawad et al. [2] achieved a removal efficiency for COD, TSS and TN of $94 \%, 98 \%$ and $77 \%$ in a combined UASB-SBR system.

\section{Conclusion}

In this study, a system consists of UASB and a cont-flow SBR was operated under different retention times. The UASB is approved as a good primary treatment unit for the cont-flow SBR system. The results indicated that the ability of the pilot plant to work under different retention times with removal efficiencies for COD, TN, and phosphate up to $96.5 \%, 62.6 \%$, and 35.9\% respectively. The cont-flow SBR system could be a competitor of the conventional SBR system and could achieve the required effluent water quality despite the spill effect of influent water coming to the system. The best cSBR hydraulic cycle time is 8 hours as it produces the best effluent wastewater quality. Furthermore, the system could meet the effluent water quality for the Egyptian law 48/1982.

\section{References}

[1] A. Elawwad, "Optimized biological nitrogen removal of high-strength ammonium wastewater by activated sludge modelling," Journal of Water Reuse and Desalination, vol. 8, no. 3, pp. 393-403, 2018.

[2] A. Moawad, U. Mahmoud, M. El-Khateeb, E. El-Molla, "Coupling of sequencing batch reactor and UASB reactor for domestic wastewater treatment," Desalination, vol. 242, pp. 325-335, 2009.

[3] A. Elawwad, M. Hazem, "Minimization of sludge production in an integrated UASB-continuous flow sequencing batch reactor system," Desalination and Water Treatment, vol. 91, pp. 206-213, 2017.

[4] A. H. Mahvi, P. Brown, F. Vaezi, F. Karakani, "Feasibility of Continuous Flow Sequencing Batch Reactor in Synthetic Wastewater Treatment," Journal of Applied Sciences, vol. 5, pp. 172-176, 2005.

[5] A. A. Khan, R. Z. Gaur, V. K. Tyagi, A. Khursheed, B. Lew, A. A. Kazmi, I. Mehrotra, "Sustainable options of post treatment of UASB effluent treating sewage-A review", Resource Conserve Recycle, vol. 55, no. 12, pp. 1232-1251, 2011.

[6] Kassab, G., Halalsheh, M., Klapwijk, A., Fayyad, M., and van Lier, J.B., "Sequential anaerobic- aerobic treatment for domestic wastewater - A review," Bio resource Technology, vol. 101, pp. 3299-3310, 2010.

[7] A. Elawwad, M. Rageb, H. Abdel-Halim, "An economical, environmental and social comparison between vacuum and gravity sewers in decentralized sanitation systems, with Egypt as a case study," Journal of Water Sanitation and Hygiene for Development, vol. 5, no. 4, pp. 614-619, 2015.

[8] E. W. Rice, R. B. Baird, A. D. Eaton, "Standard Methods for the Examination of Water and Wastewater," 23 ${ }^{\text {rd }}$ Ed., New York: WEF, 2017.

[9] G. Tchobanoglous, H. Stensel, R. Tsuchihashi, F. Burton, Wastewater Engineering: Treatment and Resource Recovery, Metcalf \& Eddy, 5th Ed., New York: McGraw-Hill Education, 2013.

[10] M. A. Moharram, H. S. Abdelhalim, and E. H. Rozaik, "Anaerobic up flow fluidized bed reactor performance as a primary treatment unit in domestic wastewater treatment," HBRC journal, vol. 12, no. 1, pp. 99-105, 2016.

[11] A. A. Khan, G. Z. Gaur, V. Diamantis, B. Lew, A. A. Kazmi, I. Mehrotra, "Continuous fill intermittent decant type sequencing batch reactor application to upgrade the UASB treated sewage," Bioprocess Biosyst Eng, vol. 36, pp. 627634, 2013.

[12] P. Torres, E. Forest, "Domestic sewage treatment in a pilot system composed of UASB and SBR reactors," Water science and technology, vol. 44, no. 4, pp. 247-256, 2001. 